\title{
MICROECONOMIA E MEIO AMBIENTE: ANÁLISE DE FUNDAMENTOS MICROECONÔMICOS INERENTES À GESTÃO AMBIENTAL NAS ORGANIZAÇÕES
}

\author{
MICROECONOMICS AND THE ENVIRONMENT: ANALYSIS OF \\ MICROECONOMIC BASIS INHERENT TO THE ENVIRONMENTAL \\ MANAGEMENT IN THE ORGANIZATIONS
}

Recebido em 15.05.10 / Aceito em 28.11.10

\begin{abstract}
Pedro dos Santos Portugal Júnior ${ }^{1}$ e Nilton dos Santos Portugal ${ }^{2}$
\end{abstract}
\section{Resumo}

A pesquisa que se segue objetiva apresentar certos fundamentos da microeconomia passíveis de aplicação e análise na gestão ambiental das empresas. Inicialmente realiza-se uma revisão sobre os conceitos e fundamentos microeconômicos, como a curva de possibilidade de produção, custos de poluição e de controle, benefícios e custos totais e marginais e teoria dos jogos; sendo, posteriormente, abordadas suas possíveis influências, inclusive com exercícios hipotéticos para compreensão da aplicabilidade dos fundamentos. Importante salientar que, na abordagem da teoria dos jogos, demonstra-se a justificativa da ação das agências reguladoras como órgãos de implementação de controles ambientais nas empresas. As ferramentas aqui abordadas são consideradas sob o aspecto teórico, mas permitem uma posterior aplicação nos processos gerenciais, na busca por tecnologias produtivas verdes e por certificações específicas. A pesquisa utiliza como metodologia o método dedutivo, buscando da teoria geral da microeconomia uma aplicação específica na gestão ambiental e, como procedimento técnico, utiliza a pesquisa bibliográfica. Verifica-se, assim, a consolidação da aplicabilidade da teoria microeconômica nos aspectos da gestão ambiental empresarial, principalmente pelo fato de que a questão ambiental atualmente influencia diretamente o planejamento estratégico das organizações.

Palavras-chave: Gestão ambiental. Microeconomia. Sustentabilidade.

\footnotetext{
1 Economista, especialista em gestão negócios, ambos pela FACECA, Varginha, MG; mestrando em Desenvolvimento Econômico pelo IE/Unicamp. Professor de Economia e Engenharia Econômica nos cursos de Administração (linha de formação Comércio Exterior), Engenharia Mecânica e Engenharia de Produção do Centro Universitário do Sul de Minas UNIS, MG. E-mail: pedrorotaract@hotmail.com

2 Administrador, MBA em finanças, mestre em Administração pela FACECA, Varginha, MG; doutorando em Administração pela UFLA. Professor de OSM e Administração nos cursos de Administração (linha de formação Comércio Exterior), Engenharia Civil e Engenharia de Produção do Centro Universitário do Sul de Minas UNIS, MG. Coordenador geral dos cursos presenciais do UNIS, MG. E-mail: nilton@unis.edu.br
} 


\begin{abstract}
The research that follows objective to present certain passive beddings of the microeconomic of application and analysis in the environmental management of the companies. Initially a revision on the microeconomic concepts and beddings is carried through as the curve of production possibility, total costs of pollution and control, benefits and costs and delinquents and theory of the games; being, later, broached its possible influences, also with hypothetical exercises for understanding the applicability of the beddings. It is important to point out that in the broaching of the theory of the games justification of the action of the regulating agencies is demonstrated to it as agencies of implementation of environmental controls in the companies. The tools broached here are considered under the theoretical aspect, but allowing a posterior application in the management process, in the search for green productive technologies and specific certifications. The research uses as methodology the deductive method, searching for general theory of the microeconomic a specific application in the environmental management; and as procedure technician the bibliographical research. The consolidation of the applicability of the microeconomic theory in the aspects of the enterprise environmental management is verified thus, mainly for the fact that the environmental question currently influences directly the strategic planning of the organizations.
\end{abstract}

Keywords: Environmental management. Microeconomic. Sustainability.

\title{
1 INTRODUÇÃO
}

A questão ambiental, já há algum tempo, passou a fazer parte do cotidiano gerencial das empresas. O desenvolvimento sustentável tomou o lugar do crescimento econômico e da simples expansão da produção, não sendo apenas mais um "modismo", mas uma necessidade sine qua non para a continuação da vida no planeta.

A noção de que o ser humano e suas atividades econômicas são os personagens principais do mundo está descartada. O que se toma como verdade neste início de século XXI é que ambos, ser humano e empresas, nada mais são que simples componentes de um sistema muito maior e complexo que necessita de equilíbrio para continuar existindo.

A variável ambiental passou a fazer parte dos processos decisórios das organizações e sua gestão é imprescindível para a manutenção e continuidade dos negócios.

Não se trata de impedir o progresso econômico, mas realizá-lo de uma forma que, segundo Donaire (1999, p. 28), "possibilita, ao mesmo tempo, eficácia e eficiência na atividade econômica e mantém a diversidade e a estabilidade do meio ambiente".

Isto posto, nota-se que a empresa tem um papel fundamental na incorporação da questão ambiental ao processo produtivo, haja vista que a produção é a peça-chave da economia. Isso deve ocorrer pelo fato de que o consumo e, principalmente, o processo produtivo causam impactos denominados externalidades negativas e os mercados falham em não as mensurá, conforme preconiza Chen (2007, p. 1), "Consumo ou produção de um agente que causa um efeito indireto sobre o consumo e produção de terceiros, e que não se reflete no mecanismo de preços de mercado".

O fato de existir essas externalidades negativas provocou uma mudança de paradigma na sociedade capitalista com relação à busca de uma manutenção do sistema sem impactos destrutivos sobre o meio ambiente. Isto ocorre, como explica Motta (2006, p. 182), pelo fato de que "na presença de externalidades, os cálculos privados de custos ou benefícios diferem dos custos ou benefícios da sociedade".

Por isso, torna-se importante analisar e discutir teorias econômicas, principalmente da microeconomia, e adaptá-las como base para o processo decisório empresarial. Pois, conforme Seiffert (1996), os problemas de alteração ambiental podem ser abordados quantitativamente de modo concreto no nível de microeconomia. 
Assim, o objetivo geral desta pesquisa é enfocar a teoria microeconômica no processo de gestão ambiental. Especificamente, objetiva-se revisar tópicos da microeconomia que se relacionam com a questão ambiental, bem como analisar como os mesmos podem influenciar na tomada de decisão da gestão ambiental na empresa.

Parte-se, portanto, do seguinte questionamento: quais os principais fundamentos microeconômicos que podem influenciar a gestão ambiental?

Para proceder tal pesquisa, utilizou-se do método dedutivo, que, conforme Munhoz (1989, p. 24), consiste em "um caminho de investigação que implicitamente admite para casos particulares a validade de conclusões geradas a partir de regras de comportamento mais gerais, ou de verdades estabelecidas", com o intuito de demonstrar a possibilidade de aplicação de determinados fundamentos microeconômicos na gestão ambiental das organizações.

Como procedimento técnico de pesquisa, foi utilizada a pesquisa bibliográfica, que, para Gil (1991), é elaborada a partir de material já publicado, principalmente de livros, artigos de periódicos, revistas especializadas e sites de internet.

\section{REVISÃO BIBLIOGRÁFICA}

Antes de adentrar nos fundamentos microeconômicos e analisar suas relações com o processo de gestão ambiental, torna-se importante abordar a própria microeconomia e seu lugar de pertinência no contexto maior da economia, bem como sua evolução de abordagem.

Segundo Rossetti (2003), a economia é a ciência que estuda a relação entre as necessidades ilimitadas dos agentes e os recursos, por sua vez limitados, utilizados para atender essas necessidades. Sua compartimentalização pode ser estabelecida da seguinte forma:

- Economia Descritiva;

- Teoria Econômica;

- Política Econômica.

A teoria econômica é subdividida em duas grandes áreas: Microeconomia e Macroeconomia. Tendo esta bifurcação da teoria surgida, conforme Garófalo (1998), nos primórdios da década de 1930.

Pindyck e Rubinfeld (2005) e Mansfield e Yohe (2006) afirmam que a microeconomia trata do comportamento das unidades econômicas individualizadas e tomadoras de decisão, sendo que tais unidades abrangem os consumidores, empresas, investidores, proprietários de fatores de produção, dentre outros. A ocupação principal desta área da teoria econômica é o estudo do agente econômico individualmente considerado.

De uma forma geral, consideram-se os agentes famílias como os responsáveis pela demanda de bens e serviços e os agentes empresas que respondem pela oferta dos mesmos. Somase a eles o agente governo, que pode tanto demandar como ofertar produtos dentro do ambiente econômico. Esses agentes interagem de forma efetiva e potencial em um ente maior, denominado mercado.

\section{ambiental \\ 2.1 As abordagens da microeconomia tradicional e da microeconomia}

Dentro da contextualização de análise da teoria da empresa, a microeconomia evoluiu, no que tange seus objetivos, em duas abordagens: tradicional e ambiental. 
Quando se trata da abordagem tradicional, duas correntes surgem com diferentes interpretações.

Vasconcellos e Garcia (2005, p. 33) indicam que a primeira "supõe o princípio de racionalidade, segundo o qual o empresário sempre busca a maximização do lucro total, otimizando a utilização dos recursos de que dispõe", apoiando-se, para isso, na teoria marginalista.

A outra corrente baseia-se, conforme Rossetti (2003), no conceito da moderna teoria da empresa, fruto de evoluções, como as teorias de Scitovski e Baumol, que afirmam que o objetivo principal da empresa pode ser outros, que não a maximização do lucro total, como, por exemplo: o aumento da participação de mercado, maximização da receita total, aumento da produção, dentre outros.

Porém, atualmente, a evolução da questão ambiental e suas implicações nos processos de tomada de decisão e produção da empresa permitiram o surgimento de uma nova abordagem da teoria microeconômica: a microeconomia ambiental. Reconhecendo-se que o fator recursos naturais não é infinito, mas está constantemente sendo esgotado, verifica-se que o processo de produção deve levar em conta a capacidade de carga do planeta.

Essa nova abordagem, segundo César (2008), aponta questões analíticas importantes, como:

- Mensuração de custos e benefícios externos: estimativa de dano ambiental, custos de mitigação, internalização das externalidades negativas, etc.;

- Valoração dos recursos naturais e do meio ambiente como bens, seja de propriedade privada ou pública: alocação intertemporal de recursos, estimativa de benefícios e custos ao longo do tempo;

- Criação de regras e direitos de propriedade apropriada para os recursos ambientais e estabelecimento de normas para uso de recursos de propriedade comum e para provisão de bens públicos: modelo de gestão da pesca e florestas, gestão de reservas naturais, etc.;

- Balanço dos custos e benefícios através de alguma forma de análise custo/benefício na tomada de decisão sobre: construção de resorts, hidroelétricas, parques eólicos, valores de não-mercado de beleza natural e biodiversidade.

Trata-se, portanto, de incorporar a variável ambiental na modelagem e análise microeconômica da teoria da empresa. Com isso, as decisões serão tomadas dentro de um contexto de racionalidade de mercado sem isolar o meio ambiente e os recursos naturais. Para isso, devem-se utilizar certos fundamentos microeconômicos básicos.

\subsection{Fundamentos da teoria microeconômica}

Dentre os inúmeros fundamentos básicos da teoria microeconômica a presente pesquisa aborda aqueles que podem apresentar uma relação direta e específica com o processo decisório de gestão ambiental. Aqui eles serão explicitados de uma maneira teórica, sendo que, no capítulo 2, serão abordadas suas possíveis aplicações.

\subsubsection{Curva de possibilidade de produção}

Consiste, segundo Vasconcellos e Garcia (2005, p. 4), "na expressão da capacidade máxima de produção da sociedade, supondo pleno emprego dos recursos ou fatores de produção 
de que se dispõe em dado momento no tempo". Trata-se de um conceito teórico que demonstra como a escassez de recursos impõe limite para a capacidade de produção.

A empresa possui um limite máximo, conhecido como produção potencial ou potencial produtivo, quando todos os fatores de produção utilizados não apresentam capacidade ociosa. Importante salientar que os fatores de produção são: Recursos Naturais (RN), Trabalho (T), Capital (K), Inovações Tecnológicas (S) e Empreendedorismo (E).

Isto posto, entende-se a curva de possibilidade de produção também como uma representação das combinações possíveis da produção de duas categorias de bens e serviços.

O gráfico 1 apresenta uma representação gráfica da curva de possibilidade de produção, com base em dois bens hipotéticos x e $y$.

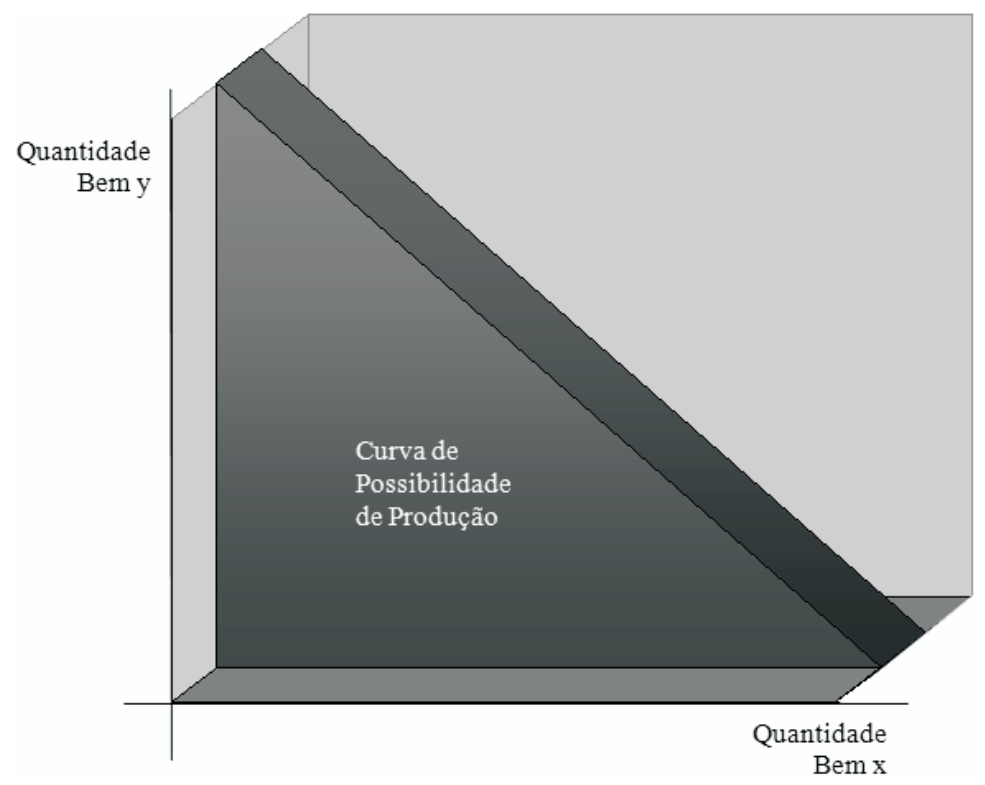

Gráfico 1 - Representação da curva de possibilidade de produção

Fonte: os autores.

A curva de possibilidade de produção pode apresentar deslocamentos para a direita, indicando, neste caso, que a economia está crescendo, ou seja, há um aumento do potencial produtivo e das combinações de produção. Vasconcellos e Garcia (2005) afirmam que isto pode ocorrer em função do aumento da quantidade física dos fatores de produção e também no caso de melhoria no aproveitamento dos fatores já existentes, devido à ação do fator inovações tecnológicas.

Porém, a curva também pode apresentar deslocamentos para a esquerda, indicando uma diminuição da produção potencial e das possibilidades de combinações produtivas. O gráfico 2 demonstra esses possíveis deslocamentos. 


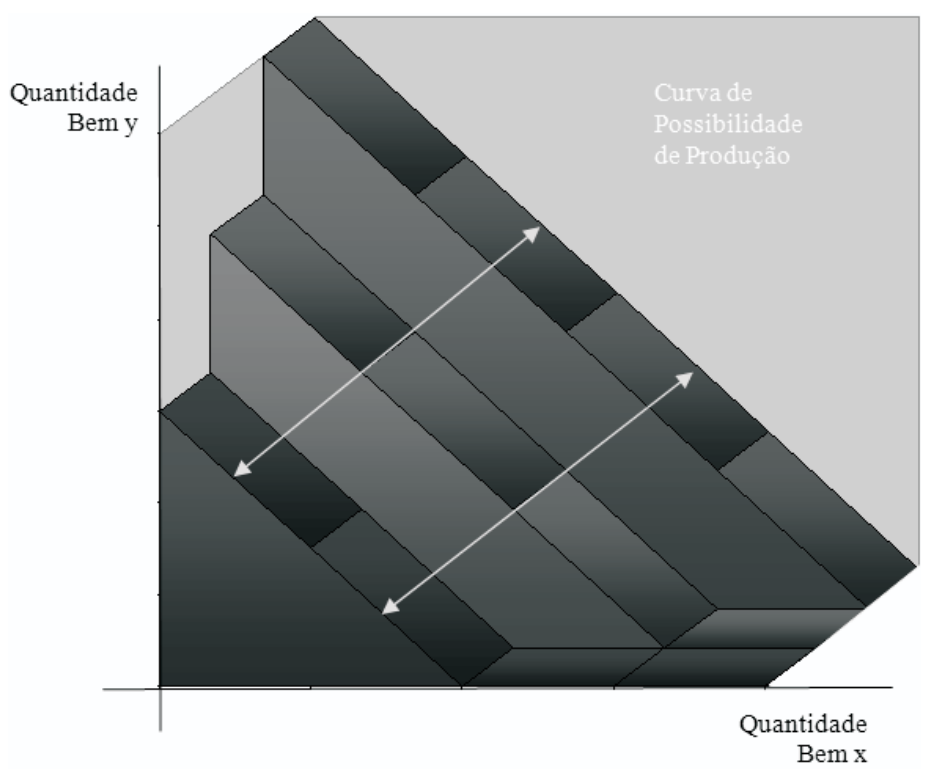

Gráfico 2 - Representação do deslocamento da curva de possibilidade de produção Fonte: os autores.

\subsubsection{Análise dos custos e benefícios sociais}

A relação entre custo e benefício do processo de produção é um importante fundamento microeconômico, principalmente quando se expande do âmbito privado para o social.

A ótica privada é aquela que aborda apenas os custos e benefícios do ponto de vista do produtor, sem considerar o que ocorreu em termos sociais em seu processo produtivo.

Mansfield e Yohe (2006) indicam que o custo e o benefício social de produzir uma mercadoria podem nem sempre ser idênticos ao custo e benefício privado (aquele incorrido pelo produtor).

Motta (1990, p. 115) afirma que a divergência entre as análises privadas e sociais "faz com que uma avaliação dos custos e benefícios de uma decisão de investimentos em termos privados não represente a variação de bem estar sob o ponto de vista da sociedade como um todo".

Isto posto, Comune (1993) explica que se deve determinar se o custo da alteração ambiental é maior ou menor que o benefício advindo desta alteração, sendo esta uma importante questão que a teoria microeconômica pode colaborar na solução.

Para realizar esta análise, deve-se considerar a análise do custo marginal social (CMgS) e do benefício marginal social (BMgS).

Pindyck e Runbinfeld (2005) explicam estas duas questões:

- Custo Marginal Social: seria a soma do custo marginal privado (específico do produtor) com o custo marginal externo (imposto à sociedade como um todo), verificado na produção de uma unidade a mais;

- Benefício Marginal Social: aquele oriundo da soma entre o benefício marginal privado (auferido pelo produtor) e o benefício marginal externo (recebido pela sociedade como um todo) advindo de uma unidade a mais produzida.

O método de confrontação do Benefício Marginal Social com o Custo Marginal Social (a ser apresentado no capítulo 2) é uma ferramenta que pode ser utilizada na tomada de decisão por parte da empresa, que utiliza este fundamento microeconômico. Sua aplicação consiste em verificar em qual ponto de utilização dos recursos naturais ocorreria o nível ótimo sob o ponto de 
visto social e não apenas privado, interligando esta análise com o benefício total recebido pela sociedade.

Para esta aplicação, torna-se necessário considerar a estrutura de medidas na análise de custo e benefício, conforme é explicitado por Hanley e Spash (1993):

* Definição do projeto a ser analisado;

* Identificação dos impactos que são economicamente relevantes;

* Quantificação física do impacto;

* Cálculo do valor monetário;

* Determinação do valor presente pelo desconto dos valores futuros;

* Ponderação dos resultados;

* Análise.

\subsubsection{Confrontação entre custos de poluição e de controle}

A análise microeconômica, ainda no âmbito da questão dos custos sociais e privados, confronta os custos relativos de emissão e redução das poluições. A teoria desta confrontação torna-se básica nos processos decisórios das empresas para aplicação de projetos de controle ambiental e verificação da viabilidade dos mesmos.

Para a realização desta análise, deve-se valorar dois tipos de custos: Custo Marginal Social da Emissão de Poluentes ou Custo Marginal da Poluição (CMgP) e o Custo Marginal do Controle da Poluição $(\mathrm{CMgC})$.

Pindyck e Rubinfeld (2005) afirmam que o CMgP indica o aumento dos prejuízos sociais das emissões de poluentes, ou seja, seus impactos na saúde da sociedade e danos econômicos aos recursos naturais; enquanto o $\mathrm{CMgC}$ é aquele custo adicional que a empresa tem para instalar equipamentos de controle de poluição, como, por exemplo, a instalação de um depurador de fumaça nas chaminés da empresa.

Mansfield e Yohe (2006) representam graficamente estes dois custos, demonstrando qual o nível ótimo de redução da poluição, exatamente onde as curvas do $\mathrm{CMgP}$ e do $\mathrm{CMgC}$ se igualam. Importante notar que este ponto ótimo não é no nível em que se elimina toda poluição, pois isso significaria o próprio fim do processo produtivo. O gráfico 3 ilustra este caso.

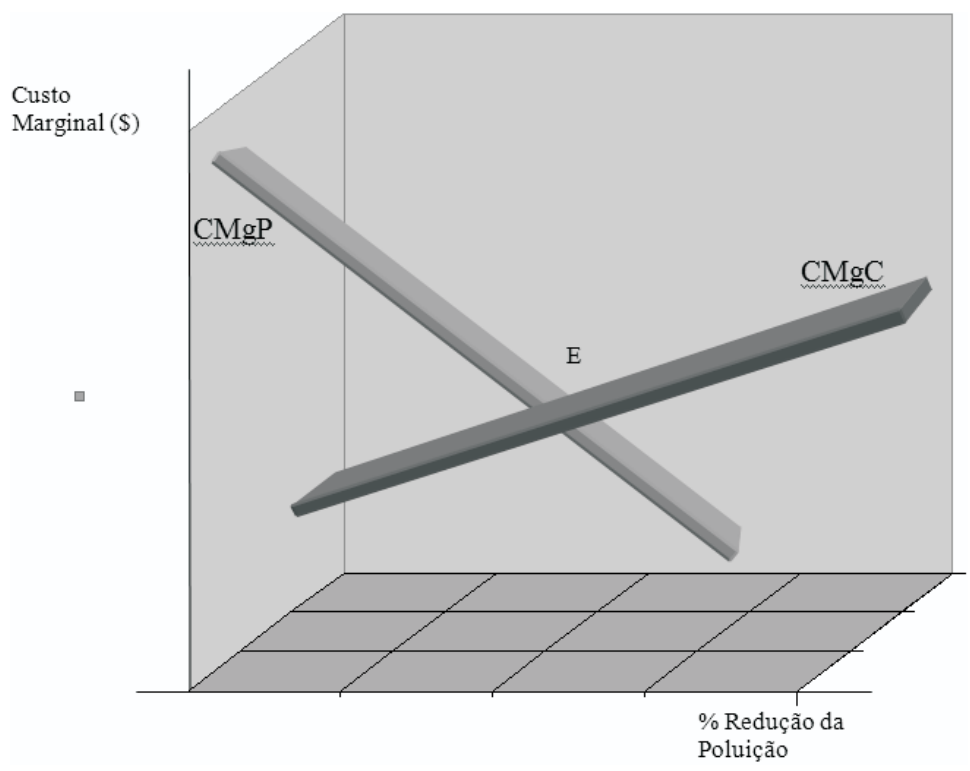

Gráfico 3 - Custos de poluição x Custos de controle Fonte: adaptado de Mansfield e Yohe (2006). 
No gráfico 3, verifica-se que o ponto ótimo em relação aos custos oriundos da poluição encontra-se no ponto E, onde ocorre a interseção das curvas de Custo Marginal de Controle $(\mathrm{CMgC})$ e de Custo Marginal de Poluição $(\mathrm{CMgP})$, indicando a porcentagem de redução da poluição que será interessante, tanto no ponto de vista dos custos privados, quanto dos custos sociais. Este ponto de minimização também pode ser demonstrado conforme a equação 1.

$$
\mathrm{CMgP}=\mathrm{CMgC}
$$

\subsubsection{Teoria dos jogos}

Um fundamento microeconômico que pode ser utilizado na gestão ambiental é a teoria dos jogos, uma das mais recentes evoluções da aplicação de conceitos e teorias matemáticas à economia e ao processo gerencial.

Para Mansfield e Yohe (2006), consiste em um instrumento que ajuda a estudar a tomada de decisões em situações nas quais existe uma mistura de conflito e cooperação.

Gremaud e Braga (1998, p. 244) afirmam que a teoria dos jogos "tem como objetivo a análise de problemas em que existe uma interação entre os agentes, onde as decisões de um indivíduo, firma ou governo afetam e são afetadas pelas decisões dos demais agentes".

Esta teoria trabalha com as questões decisórias e estratégicas dos ambientes organizacionais e sociais. Sua análise permite uma antecipação de resultados que auxiliam os gestores privados e sociais na tomada de decisão.

A utilização da teoria dos jogos exige o conhecimento prévio de seus conceitos básicos.

Primeiramente, os elementos componentes de um jogo, que, conforme Gremaud e Braga (1998), são:

- os jogadores ou agentes econômicos;

- o conjunto de ações possíveis para cada jogador;

- o conjunto de informações disponíveis para cada agente (completa ou incompleta);

- os resultados possíveis (payoff's) decorrentes da interação das ações.

A tipologia dos jogos também é importante para uma correta análise do processo decisório. Isto posto, os jogos podem ser cooperativos ou não cooperativos, sendo assim definido

\footnotetext{
Um jogo cooperativo é aquele no qual os participantes podem negociar contratos vinculativos de cumprimento obrigatório que lhes permitam planejar estratégias em conjunto. Um jogo não cooperativo ocorre quando não é possível a negociação de tais contratos entre os participantes. (PINDYCK; RUBINFELD, 2005, p. 408).
}

Ho e Weigelt (1999) apresentam duas considerações básicas importantes sobre a teoria dos jogos. Primeiro, quanto a sua forma de representação, que pode ser ampliada (também chamada de árvores de decisão ou extensiva) ou normal (também denominada matricial). Segundo, quanto a sua característica temporal, em que o jogo pode ser sequencial (quando um agente conhece a decisão do outro antes de definir a sua) ou simultâneo (em que as decisões são estabelecidas concomitantemente, sem que um saiba a decisão do outro).

Importante salientar que os jogos representados na forma normal/matricial sempre serão simultâneos. 
Ainda na abordagem dos conceitos básicos da teoria dos jogos devem-se apresentar os tipos de soluções ou estratégias, cujas mais conhecidas, segundo Gremaud e Braga (1998) são:

- Dominantes: quando os resultados obtidos com sua utilização são melhores em relação aos resultados obtidos com outra estratégia, qualquer que seja a atuação dos demais jogadores. Deve-se destacar que esta nem sempre é a solução considerada ótima no conceito de Pareto;

- "Maxmin": é o caso em que o jogador procura maximizar o mínimo para si, independente das estratégias dos outros jogadores. É aquela que garante um ganho mínimo para o jogador;

- Nash: também conhecida como solução de equilíbrio, quando a combinação de estratégias escolhidas leva a um resultado no qual nenhum dos agentes individualmente se arrepende. Em suma, o jogador não poderia melhorar sua situação unilateralmente modificando a estratégia escolhida. Seu nome advém do matemático americano e Nobel de Economia John Forbes Nash.

Os estudos recentes sobre a teoria dos jogos vêm demonstrando aplicações nos mais diversos campos acadêmicos além da economia e da administração, como, por exemplo, na ciência política, na ética, na filosofia, no jornalismo, dentre outros.

Os fundamentos microeconômicos tratados neste item revisional serão vistos no próximo sob a ótica de suas influências na tomada de decisão da gestão ambiental.

\section{APLICAÇÕES DA MICROECONOMIA NA GESTÃO AMBIENTAL}

Este item apresenta as possibilidades de aplicação das questões da teoria microeconômica no contexto da gestão ambiental na empresa. Essas aplicações são apresentadas sob enfoque teórico, porém com possibilidade de serem colocadas em prática nos processos de tomada de decisão.

Para Donaire (1999), a incorporação da variável ambiental na prospecção de negócios pelas organizações é uma realidade sobre a qual as empresas devem manter atenção especial, além de ser uma maneira de demonstrar uma postura responsável sobre a questão do meio ambiente.

Isto posto, as empresas devem utilizar-se de mecanismos específicos para essas análises, e os fundamentos microeconômicos apresentados servem de base para estes mecanismos.

\subsection{Valoração ambiental pela curva de possibilidade de produção}

Pesquisas recentes buscam estabelecer formas de imputar ou mensurar as perdas que o meio ambiente sofre devido às degradações realizadas, principalmente pelo setor produtivo. Essa atribuição de valores tem por principal objetivo servir de base para comparações da depleção entre diferentes processos de produção e também para que os gestores possam verificar a magnitude do impacto das ações produtivas no meio ambiente.

A importância dada a este tema é explicada por Gonçalves (2006, p. 31): "a necessidade de se valorar os impactos ambientais independente da técnica utilizada visa garantir recursos naturais para as gerações futuras, fato denominado desenvolvimento sustentável, que se tornou uma das prioridades mundiais". Ou seja, o nível de produção deve ser definido de acordo com a capacidade de suporte dos ecossistemas.

Nogueira et al. (1998) afirmam que a valoração econômica é o último passo da análise, antes deve ser realizado uma medição dos efeitos físicos, químicos e biológicos das atividades e das perdas. 
Uma técnica de se valorar economicamente as perdas ambientais, baseada na teoria microeconômica, seria através da utilização da curva de possibilidade de produção. Conforme visto no subitem 1.2.1, esta curva demonstra a capacidade máxima de produção de uma sociedade ou de uma empresa e seu deslocamento ocorre através do aumento da dotação de fatores e da ação das inovações tecnológicas. Porém o fator Recursos Naturais, quando sofre perdas e degradações, diminui sua disponibilidade e, consequentemente, seu potencial no processo produtivo também irá diminuir, não apenas de maneira direta, mas também de maneira indireta.

Este impacto será determinado pela elasticidade fator-produto, que demonstra a relação incremental entre a variação percentual do fator de produção $(\Delta \% \mathrm{~F})$ e seu impacto na variação percentual da quantidade de produção $(\Delta \% \mathrm{QP})$.

$$
\varepsilon y / F=\Delta \% Q P / \Delta \% F
$$

Sendo $>1$ a quantidade produzida é elástica ao fator;

$=1$ a elasticidade é unitária;

$<1$ a quantidade produzida é inelástica ao fator.

Produtos que têm suas quantidades produzidas elástica às variações do fator Recursos Naturais tendem a ter um impacto maior em sua curva de possibilidade de produção devido à degradação ambiental

Isto posto e sendo possível a demonstração do potencial produtivo da empresa por meio da curva de possibilidade de produção, a diminuição do fator Recursos Naturais poderia ser mensurada de duas formas.

A primeira se dá através de uma diminuição da curva de possibilidade de produção, ocorrendo um deslocamento da curva para a esquerda, sendo esta diminuição ocasionada por perdas ambientais, ou seja, diminuição do potencial produtivo do fator Recursos Naturais utilizado pela empresa. O gráfico 4 demonstra este caso.

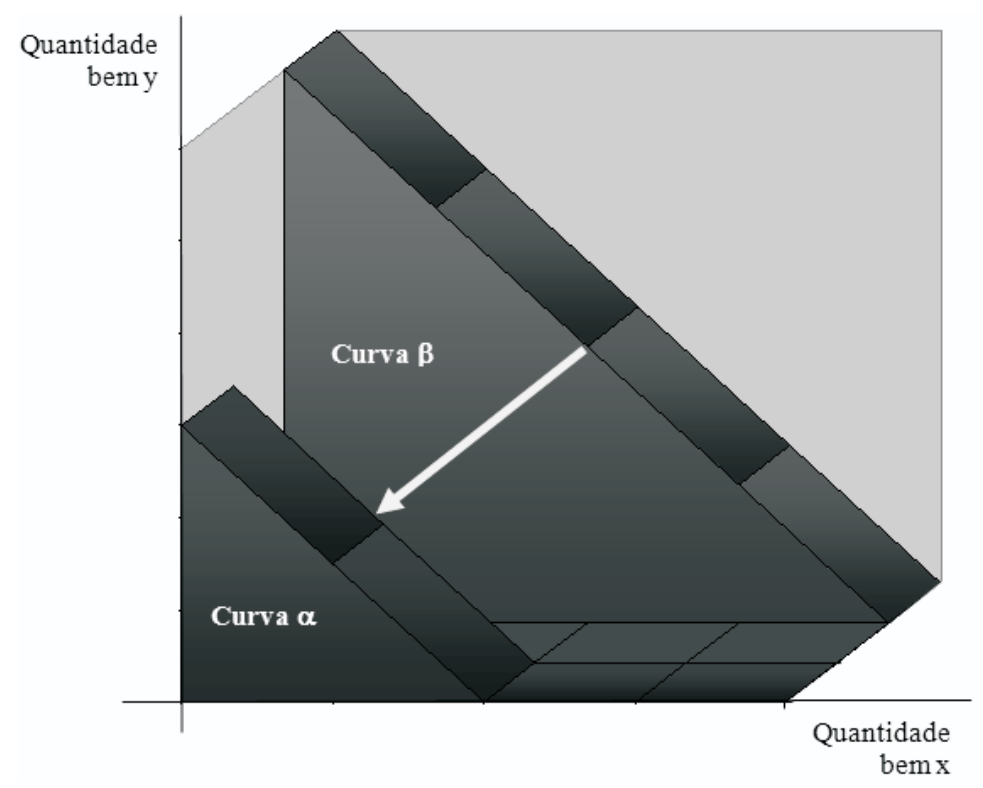

Gráfico 4 - Deslocamento da curva de possibilidade de produção Fonte: os autores.

Rev. Adm. UFSM, Santa Maria, v. 3, n. 3, p. 393-410, set./dez. 2010 
Nesse caso, ocorre um defice produtivo, ocasionado por uma diminuição do fator recursos naturais (RN), devido às perdas ou degradações ambientais em uma proporção maior que a variação positiva dos fatores capital $(\mathrm{K})$ e trabalho $(\mathrm{T})$, mesmo influenciados diretamente pelas inovações tecnológicas $(\mathrm{S})$, conforme pode ser apresentado no modelo abaixo:

$$
(-\Delta R N)>(+\Delta K+\Delta T) D S
$$

Utilizando um exemplo hipotético, pode-se ilustrar o uso da curva: imaginando que a curva b apresente, como seus extremos, 20 unidades do bem x cujo preço unitário seja $\$ 10,00$ e 30 unidades do bem y, cujo preço unitário é $\$ 5,00$; e a curva a com extremos de 15 unidades do bem x e 26 unidades do bem y, considerando o mesmo preço para ambos os bens, evitando a ação da inflação do período. Com estes dados, pode-se calcular o defice produtivo da seguinte forma:

$$
\beta-\alpha=[(\Delta Q x) \cdot P x]+[(\Delta Q y) \cdot P y]
$$

Sendo Qx: quantidade de bem x, Px: o preço unitário do bem x, Qy: a quantidade de bem y e Py: o preço unitário do bem y.

Com isso, o cálculo apresentaria a seguinte forma:

$$
\begin{gathered}
{[(20-15) \cdot 10,00]+[(30-26) \cdot 5,00]=[5 \cdot 10,00]+[4.5,00]=50,00+20,00} \\
\beta-\alpha=\$ 70,00
\end{gathered}
$$

Este resultado do exemplo hipotético mostra o impacto na produção causado pelas perdas ambientais, ou seja, uma forma de valorar estas perdas, que causaram um defice produtivo no valor de $\$ 70,00$.

b) A outra forma de mensuração seria quando ocorre um crescimento da produção, ou seja, um deslocamento da curva de possibilidade de produção para a direita, mas este deslocamento é menor do que o previsto devido às perdas ambientais.

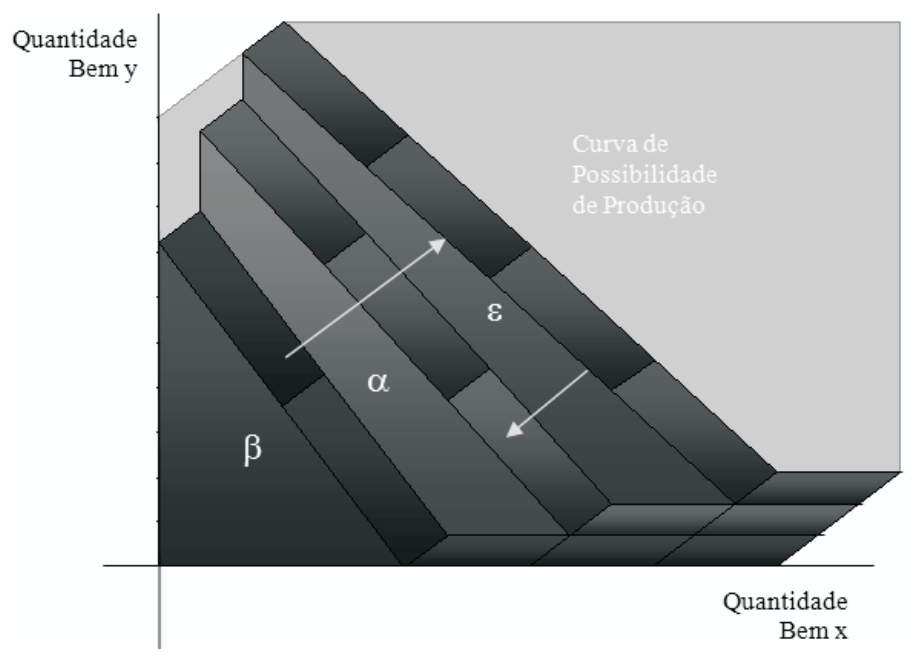

Gráfico 5- Deslocamentos da curva de possibilidade de produção Fonte: os autores. 
Isto de deve ao fato de que a variação positiva dos fatores capital (K) e trabalho (T), influenciados pelas inovações tecnológicas (S), ocorre em uma proporção maior que a variação negativa do fator recursos naturais (RN), conforme demonstrado pelo modelo:

$$
(-\Delta R N)<(+\Delta K+\Delta T) \Delta S
$$

Porém, como ocorrem perdas ambientais (afetando o fator recursos naturais), o crescimento da produção não atinge o potencial produtivo representado pela curva e (fruto do crescimento dos demais fatores e representado pelo deslocamento de $\beta$ para $\varepsilon$ ), mas ocorre uma retração do crescimento, constituindo, assim, uma capacidade efetiva de produção, representada no gráfico pela curva a (deslocamento da curva e para a).

Nesse caso, as perdas ambientais podem ser valoradas pelo diferencial entre o potencial produtivo e a capacidade efetiva de produção, ou seja, a diferença entre as curvas $\varepsilon$ e $\alpha$, utilizando, para isso, o mesmo procedimento de cálculo do caso (a) deste item.

Utilizando um exemplo hipotético, imagina-se que a curva $\varepsilon$ apresente como extremos 50 unidades do bem $x$ ao preço unitário de $\$ 8,00$ e 30 unidades do bem y ao preço unitário de $\$ 6,00$; já a curva $\alpha$ tem por extremos 44 unidades de bem x e 28 unidades de bem y, mantidos os mesmos preços unitários. Sendo assim a valoração das perdas ambientais apresenta o seguinte cálculo:

$$
\begin{gathered}
{[(50-44) \cdot 8,00]+[(30-28) \cdot 6,00]=[6 \cdot 8,00]+[2 \cdot 6,00]=48,00+12,00} \\
\varepsilon-\alpha=\$ 60,00
\end{gathered}
$$

Portanto, a diferença entre o potencial produtivo e a capacidade efetiva de produção, que representa o valor das perdas ambientais, é de $\$ 60,00$.

Esses casos, estudados e exemplificados de maneira hipotética, podem ser aplicados em nível prático quando a empresa deseja mensurar as perdas ambientais provocadas, com base no impacto no seu processo produtivo, seja diminuindo a quantidade produzida de seus bens, seja fazendo com que haja diferença entre o potencial produtivo e a capacidade efetiva de produção.

Com isso os gestores podem tomar a decisão de investir na mitigação dos impactos ambientais causados pela empresa até o ponto em que estes diminuíram sua capacidade produtiva, a fim de recuperar o potencial de produção perdido.

\subsection{Confrontação entre $B M g S$ e $C M g S$}

Este método apresenta a confrontação entre Custo Marginal Social (CMgS) e Benefício Marginal Social (BMgS) e ainda propõe apresentar o reflexo no benefício total que a sociedade obtém na utilização dos recursos naturais. Portanto, usa-se o conceito de marginal a fim de demonstrar a partir de que ponto o benefício total apresenta mudanças e como ocorre essa influência.

A utilização e análise deste método devem ser realizadas a partir da construção de dois gráficos interligados, que demonstram as evoluções do CMgS e BMgS e os impactos no benefício total advindos da utilização dos recursos naturais.

Os gráficos 6 e 7 ilustram a utilização do método de confrontação BMgS e CMgS. 


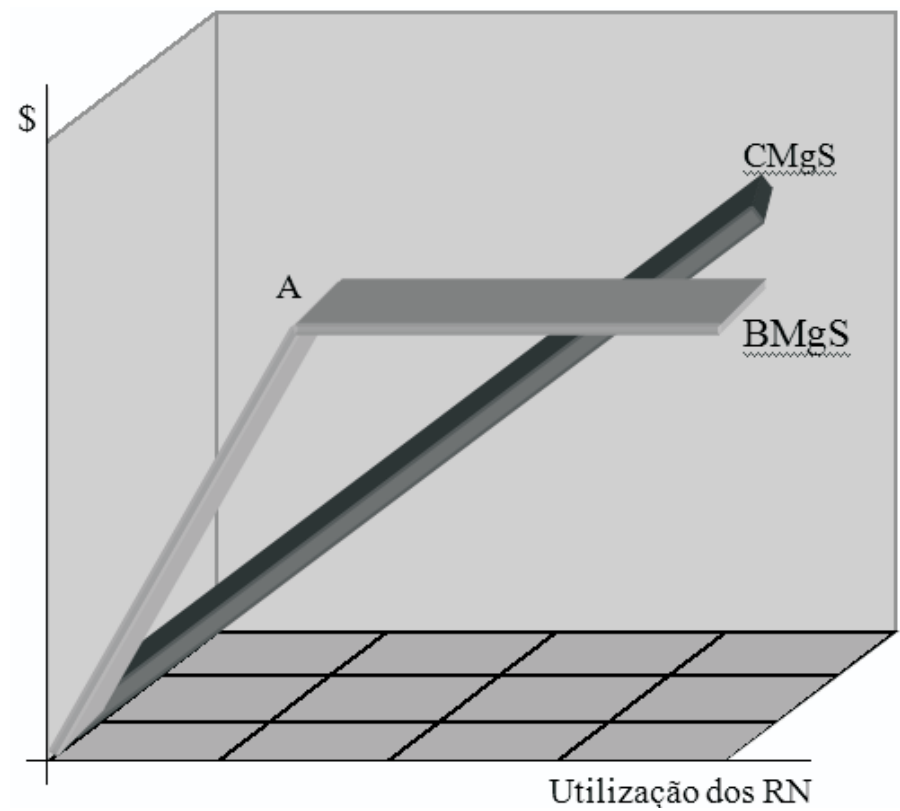

Gráfico 6 - Evolução do CMgS e BMgS

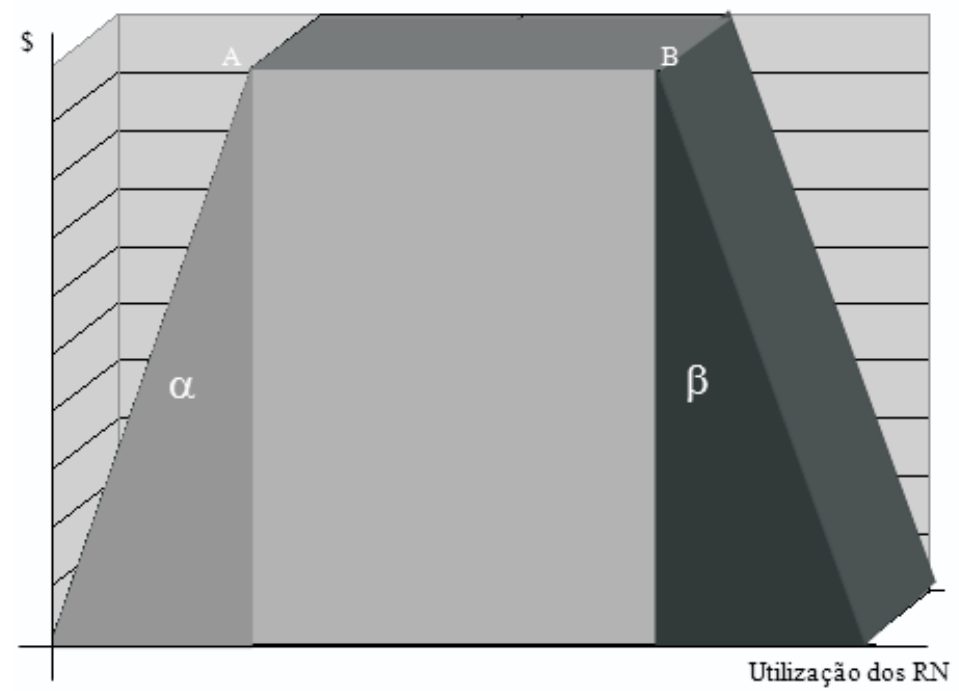

Gráfico 7 - Evolução do benefício total Fonte: os autores

Nos gráficos 6 e 7, demonstra-se a aplicabilidade do método, cabendo, agora, analisá-lo em relação as seus pontos principais e respectivos significados: 
- O gráfico 6 representa a evolução do BMgS e CMgS, onde no ponto A ocorre uma inflexão na evolução do BMgS, determinando o nível de saturação dos benefícios advindos da utilização dos recursos naturais, pois a partir deste ponto a utilização de uma unidade adicional de RN não implicará em aumento do benefício social. A partir da interseção das duas curvas, o CMgS passa a ser maior que o BMgS, sendo assim, acima deste nível de utilização de RN, o custo de uma unidade a mais será maior que o benefício recebido (que neste ponto já está saturado). Esta interseção representa o último nível em que se poderá utilizar o recurso natural;

- O gráfico 7 demonstra o comportamento e evolução do benefício total advindo da utilização de RN em paralelo à evolução dos $\mathrm{CMgS}$ e BMgS do mesmo. O ponto A (no mesmo nível do ponto A do gráfico 6) representa o ponto de melhor utilização dos recursos naturais, pois até nele o benefício total é crescente devido ao nível crescente do BMgS. A partir deste ponto A e até que o $\mathrm{CMgS}$ passe o BMgS no ponto de interseção, o benefício total permanecerá constante. O espaço representado por a representa o melhor nível de utilização dos recursos naturais. A partir de determinado ponto (no mesmo nível do ponto interseção do gráfico 6), o benefício total passa a ser decrescente, pois o CMgS passa a ser maior que o BMgS da utilização de RN. Portanto o nível b representa o reflexo maior das perdas ambientais e utilização desenfreada e não sustentável de RN.

O uso deste método justifica-se com base na afirmação de Motta (2006, p.186) que diz: "quando a disponibilidade de um bem ou serviço ambiental derivado de um recurso ambiental é alterada, a valoração dessa variação deverá, então, mensurar as variações de bem-estar em que esta alteração de disponibilidade resultou". Entende-se por variações de bem-estar o benefício que a sociedade recebe deste processo de produção.

Ainda com relação ao gráfico 6 , podem-se apresentar considerações matemáticas fundamentando-o, dado que o BMgS é uma função da Utilização dos Recursos Naturais (RN) e esta relaciona-se diretamente com a utilidade $(U)$ e a qualidade $(Q)$ do recurso natural e, indiretamente, com o nível populacional $(\mathrm{P})$ pode-se descrevê-lo da seguinte forma:

$$
\begin{aligned}
& B M g S=f(R N) \\
& R N=f(U, Q / P)
\end{aligned}
$$

O ponto de cruzamento entre as duas curvas de $\mathrm{CMgS}$ e BMgS indicaria a capacidade máxima de utilização dos recursos naturais, pois, após este ponto, os custos sociais passarão a ser maiores que os benefícios sociais, causando uma depleção muito grande do meio ambiente. Sendo o CMgS definido também em função da Utilização dos Recursos Naturais (RN), porém, relacionada agora diretamente com a valoração de sua degradação (D), indicado como:

$$
\begin{gathered}
C M g S=f(R N) \\
R N=f(D)
\end{gathered}
$$

A área existente entre as curvas de BMgS e CMgS indicaria o excedente de utilização dos recursos naturais dentro da capacidade máxima dos recursos naturais, sendo determinada pela integral de suas respectivas equações diferencial de RN, assim demonstrada:

$$
\int_{0}^{\kappa}[B m g S \quad C M g S] d R N
$$


Sendo $\kappa$ indicado pelo ponto de interseção das curvas de BMgS e CMgS em termos de utilização de recursos naturais.

Dá-se uma atenção maior na fundamentação matemática do gráfico 6 por apresentar diretamente a confrontação do $\mathrm{BMgS}$ e CMgS, que é o principal objetivo deste método, sendo o gráfico 7 um reflexo desta confrontação, não necessitando, assim, uma comprovação matemática deste último.

Isto posto, verifica-se que a alocação de recursos pelas empresas deve ser orientada levando-se em consideração os benefícios e os custos sociais em vez de apenas seus valores privados. Portanto, a sociedade não estaria sofrendo consequências graves da utilização desenfreada dos recursos naturais até o ponto em que o $\mathrm{CMgS}=\mathrm{BMgS}$, indicando, assim, o nível ótimo microeconômico do processo produtivo.

\subsection{Teoria dos jogos no contexto da gestão ambiental}

Conforme descrito no subitem 2.2.4, a teoria dos jogos é uma ferramenta auxiliar do processo decisório. Nesta pesquisa será apresentada uma análise desta teoria no contexto da questão do meio ambiente entre as empresas e a sociedade, demonstrando a importância da regulação ambiental no mercado e a justificativa de que o planejamento estratégico das empresas é que deve se adaptar à gestão ambiental e não o contrário.

Para realizar esta análise, serão comparados os possíveis resultados a serem obtidos pela empresa no processo produtivo com e sem a exigência de controle ambiental e os impactos para a sociedade também com e sem a mesma exigência. Para isso, será adotada uma matriz com dados hipotéticos para ilustrar a questão.

\section{SOCIEDADE}

Exigir controle ambiental Não exigir controle ambiental

EMPRESAS

\begin{tabular}{r|c|c|}
\multicolumn{1}{c}{} & Exigir controle ambiental & Não exigir controle ambiental \\
\cline { 2 - 3 } Produzir & $\mathrm{Li}-\mathrm{Cc} /-5 \%$ & $\mathrm{Li} /-50 \%$ \\
& $0 / 10 \%$ & $0 / 0$ \\
\cline { 2 - 3 } Não produzir & & \\
\cline { 2 - 3 } & &
\end{tabular}

Onde Li $=$ Lucro inicial e Cc $=$ Custos de Controle Ambiental e \% representam a variação da qualidade ambiental para a sociedade.

Fonte: adaptado de Mansfield e Yohe (2006).

Analisando a matriz de pay-off's apresentada, pode-se concluir as seguintes questões:

1) A empresa terá como estratégia dominante PRODUZIR até o ponto em que $\mathrm{CMgP}=\mathrm{CMgC}$ (equação 1), ou seja, até que os custos de controle ambiental permitam que o lucro final ( $\mathrm{Li}$ - Cc) esteja acima do custo de oportunidade e da taxa de atratividade do mercado;

2) Para a sociedade, a estratégia dominante deverá EXIGIR CONTROLE AMBIENTAL, pois, neste caso, a variação percentual da qualidade ambiental será de $-5 \%$ a $+10 \%$, o que significa um resultado melhor em relação à outra estratégia, em que as variações são de $-50 \%$ a 0 ;

3) As estratégias citadas como dominantes para ambos também podem ser consideradas um equilíbrio de Nash, pois tanto a empresa como a sociedade não se arrependerão de terem tomado as referidas decisões; 
4) Cumpre salientar que a estratégia ótima não coincide com a dominante, pois, para a empresa, o ótimo seria a estratégia de produzir e a sociedade não exigir controle ambiental (Li / -50\%); já para a sociedade o ótimo ocorreria pela estratégia de exigir controle ambiental e a empresa não produzir (0 / 10\%).

Em suma, a empresa, na maioria dos casos, optará pela produção, gerando poluição, porém tendo que a controlar pelas exigências sociais. Já a sociedade deverá sempre exigir o controle ambiental, para que a qualidade do meio ambiente não se deteriore em níveis cada vez mais altos. Isto posto, para que a sociedade faça esta exigência, deverá estar amparada nas agências reguladoras do meio ambiente, devido principalmente à questão da assimetria de informações que existe entre empresas e sociedade.

A importância dessas agências reguladoras justifica-se pela afirmação de Motta (2006, p. 185): "devido ao caráter difuso do problema ambiental, observa-se um número elevado de partes afetadas e geradoras de externalidades". Sendo assim, este tipo de regulação pode especificar direitos completos de propriedade dos recursos ambientais, tornando possível a intervenção e negociação entre as partes envolvidas: empresas e sociedade.

Ainda fundamentando esta questão, Pondé (1994) afirma que a economia não pode ser entendida como um sistema autorregulado, mas deve apresentar formas de intervenção política e estabelecimento de instituições que regulem a relação entre a sociedade e as empresas.

Esta análise pela teoria dos jogos evidencia que o processo produtivo não irá parar, mas adaptar-se-á às questões ambientais. Perdas ocorrerão, mas deve-se valorá-las para que as exigências de controle impeçam que estas perdas (custos) sejam maiores que os ganhos (benefícios). Ou seja, minimizar as perdas sem comprometer completamente os ganhos, implantando, assim, o trinômio: Gestão Ambiental-Controle-Produção.

\section{CONCLUSÃO}

Esta pesquisa teve por intuito apresentar os principais fundamentos da teoria microeconômica e suas relações com o processo de gestão ambiental na empresa, como uma forma de consolidar a análise da microeconomia ambiental. Objetivou-se especificar instrumentos, advindos desta teoria, que permitem a tomada de decisão considerando os impactos ambientais da produção.

A evolução das tecnologias verdes de produção já faz parte da realidade de muitas empresas, dos mais diferentes segmentos. Isso já pode ser verificado em muitos processos de financiamentos junto a órgãos governamentais, que apenas concedem o crédito a empresas que estejam em situação regular nas agências ambientais. As próprias agroindústrias e demais empresas agrícolas, muitas vezes, têm de comprovar a averbação de reservas ambientais legais em sua área de propriedade para que possam ter acesso a empréstimos rurais.

Os próprios sistemas de certificação das séries ISO 14000 e ISO 26000 (este ainda em processo de estudo para implantação) atestam a importância da questão ambiental no processo produtivo e constituem condições essenciais para que uma empresa possa internacionalizar-se ou, até mesmo, tornar-se fornecedora para grandes empresas e para o próprio setor público.

O uso de fundamentos, como estes especificados no artigo, auxilia na internalização da questão ambiental no planejamento estratégico da empresa, ou seja, a busca pela sustentabilidade direciona as empresas a estruturarem seus planejamentos conforme as questões e necessidades 
ambientais. Isso constitui um importante desafio para as organizações que somente será vencido com a utilização de instrumentos corretos e bem fundamentados.

Muitas evoluções ainda deverão ocorrer para que a gestão ambiental obtenha ainda mais notoriedade em todos os setores e segmentos econômicos, porém o que se deve ressaltar são as mudanças implementadas na consideração da questão do meio ambiente e de sua importância para se atingir o desenvolvimento sustentável. Para isso, ferramentas baseadas nas teorias econômicas e administrativas deverão ser criadas, adaptadas e aplicadas para que estes objetivos possam ser atingidos.

\section{REFERÊNCIAS BIBLIOGRÁFICAS}

CÉSAR, Rogério. A economia e o meio ambiente. 2008. 23 slides. Nivelamento do PRODEMA: Macroeconomia. 2008.

CHEN, Chia-Hui. Chap 16: Why markets fail? In: Principles of microeconomics. Massachusetts: MIT, 2007. Disponível em: < http://ocw.mit.edu>. Acesso em: 31 dez. 2008.

COMUNE, Antônio Evaldo. Meio ambiente, economia e economistas: uma breve discussão. In: MAY, Peter Herman; MOTTA, Ronaldo Serôa da (Org.). Valorando a natureza: análise econômica para o desenvolvimento sustentável. Rio de Janeiro: Campus, 1993. p. 45-59.

DONAIRE, Denis. Gestão ambiental na empresa. 2. ed. São Paulo: Atlas, 1999.

GARÓFALO, Gílson de Lima. Considerações sobre a microeconomia. In: PINHO, Diva Benevides; VASCONCELLOS, Marco A. Sandoval de. Manual de economia: equipe de professores da USP. 3. ed. São Paulo: Saraiva, 1998. p. 69-80.

GIL, Antônio Carlos. Técnicas de pesquisa em economia. 2. ed. São Paulo: Atlas, 1991.

GONÇALVES, Gabrielle Leonel. Economia e meio ambiente: a valoração econômica e sua contribuição para o desenvolvimento sustentável. 2006. 54 f. Monografia (Graduação em Ciências Econômicas)-Faculdade Cenecista de Varginha, Varginha, 2006.
GREMAUD, Amaury Patrick; BRAGA, Márcio Bobick. Teoria dos jogos: uma introdução. In: PINHO, Diva Benevides; VASCONCELLOS, Marco A. Sandoval de. Manual de economia: equipe de professores da USP. 3. ed. São Paulo: Saraiva, 1998. p. 243-260.

HANLEY, Nick; SPASH, Clive L. Cost-benefit analysis and the environment. England: Edward Elgar, 1993.

HO, Teck Hua; WEIGELT, Keith. Teoria dos jogos e estratégia competitiva. In: DAY, George; REIBSTEIN, David. A dinâmica da estratégia competitiva. Rio de Janeiro: Campus, 1999. p. 135-158.

MANSFIELD, Edwin; YOHE, Gary. Microeconomia. 11. ed. São Paulo: Saraiva, 2006.

MOTTA, Ronaldo Serôa da. Análise de custobenefício do meio ambiente. In: MARGULLIS, Sérgio (Org.). Meio ambiente: aspectos técnicos e econômicos. Rio de Janeiro: IPEA, 1990. p. 109134.

Economia ambiental. Rio de Janeiro: FGV, 2006.

MUNHOZ, Dércio Garcia. Economia aplicada: técnicas de pesquisa e análise econômica. Brasília: UnB, 1989. 
NOGUEIRA, Jorge Madeira; MEDEIROS, Marcelino Antônio Asano de; ARRUDA, Flávia Silva Tavares de. Valoração econômica do meio ambiente: ciência ou empirismo? In: REUNIÃO ANUAL DA SOCIEDADE BRASILEIRA PARA O PROGRESSO DA CIÊNCIA (SBPC), 50., 1998, Natal. Anais eletrônicos... Brasília. Disponível em: <http:// www.unb.br>. Acesso em: 08 mar. 2007.

PINDYCK, Robert S; RUBINFELD, Daniel L. Microeconomia. 6. ed. São Paulo: Pearson Prentice Hall, 2005.

PONDÉ, João Luiz S. P. de. Coordenação, custos de transação e inovações institucionais. Texto para discussão IE Unicamp n. 38. Campinas, 1994.

ROSSETTI, José Paschoal. Introdução à economia. 20. ed. São Paulo: Atlas, 2003.

SEIFFERT, Nelson Frederico. Uma contribuição ao processo de otimização do uso dos recursos ambientais em microbacias hidrográficas. 1996. 150 f. Tese (Doutorado em Engenharia de Produção)-Centro Tecnológico da Universidade Federal de Santa Catarina, Florianópolis, 1996.

VASCONCELLOS, Marco Antônio Sandoval de; GARCIA, Manuel Enriquez. Fundamentos de Economia. 2. ed. São Paulo: Saraiva, 2005. 